\title{
An effective and efficient method to design services: empirical study for services by an investment-machine manufacturer
}

\author{
Tomohiko Sakao, Herbert Birkhofer, Veselin Panshef and Edgar Dörsam
}

\section{Linköping University Post Print}

N.B.: When citing this work, cite the original article.

Original Publication:

Tomohiko Sakao, Herbert Birkhofer, Veselin Panshef and Edgar Dörsam, An effective and efficient method to design services: empirical study for services by an investment-machine manufacturer, 2009, International Journal of Internet Manufacturing and Services, (2), 1, 95110.

http://dx.doi.org/10.1504/IJIMS.2009.031342

Copyright: Inderscience http://www.inderscience.com/

Postprint available at: Linköping University Electronic Press http://urn.kb.se/resolve?urn=urn:nbn:se:liu:diva-73931 


\title{
An effective and efficient method to design services: empirical study for services by an investment- machine manufacturer
}

\section{Tomohiko Sakao}

Institute for Product Development and Machine Elements, Darmstadt University of Technology, Magdalenenstrasse 4, 64289 Darmstadt, Germany, and

Department of Management and Engineering, Linköping University 58183 Linköping, Sweden

Phone: +46-13-282287 E-mail: tomohiko.sakao@liu.se

\section{Herbert Birkhofer}

Institute for Product Development and Machine Elements, Darmstadt University of Technology, Magdalenenstrasse 4, 64289 Darmstadt, Germany Fax: +49-6151-16-3355 E-mail: birkhofer@pmd.tu-darmstadt.de

\section{Veselin Panshef and Edgar Dörsam}

Institute for Printing Machines and Printing Processes, Darmstadt University of Technology, Magdalenenstrasse 2, 64289 Darmstadt, Germany Fax:+49-6151-16-3632 E-mail: veselin.panshef@kba.com, doersam@idd.tudarmstadt.de

\begin{abstract}
Knowledge in practice on how to design offerings of services and products effectively and efficiently is demanded in manufacturing industries. This article discusses some empirical results obtained from designing services at a manufacturer, who had implemented information-communication networks to their customers and adopted a structured method to design services. It demonstrates that the method worked for a real-scaled problem to generate several effective solutions with input of approximately five person-months. This is contributed to largely by the technique addressing customer value through extension of Quality Function Deployment. Simultaneously, it is pointed out that special efforts are needed to prepare the ontology used to describe the model.
\end{abstract}

Keywords: Servicification of manufacturers; customer value; remote service; service activity; physical product; Product/Service System; Integrated Product Service Engineering; Quality Function Deployment; Service Explorer

Reference to this paper should be made as follows: Sakao, T., Birkhofer, H., Panshef, V., and Dörsam, E. (2009) 'An effective and efficient method to design services: empirical study for services by an investment-machine manufacturer', Int. J. Internet Manufacturing and Services, Vol. X, No. Y, pp.000-000.

Biographical notes: Tomohiko Sakao has been professor at the Department of 


\section{T. Sakao, H. Birkhofer, V. Panshef, and E. Dörsam}

Management and Engineering at Linköping University in Sweden since 2007. $\mathrm{He}$ received a $\mathrm{BS}$, an $\mathrm{MS}$, and a $\mathrm{Ph}$. D. in precision machinery engineering from the University of Tokyo in 1993, 1995, and 1998 respectively. He was a researcher at Mitsubishi Research Institute, Inc., Japan from 1998 to 2005, and conducted research as a guest researcher at Institute for Product Development and Machine Elements, Darmstadt University of Technology from 2005 to 2007. His research interests include industrial management (e.g., Integrated Product Service Engineering, product/service customization), environmental engineering, and intelligent machinery.

Prof. Dr.-Ing. Dr.h.c. Herbert Birkhofer is chair of Institute for Product Development and Machine Elements, Darmstadt University of Technology. $\mathrm{He}$ received Dr. Eng. at the faculty for mechanical engineering and electrotechnology of the Technical University of Braunschweig, Germany in 1980. He also received Honorable doctorate from the University of Vészprem, Hungary in 2003. He was awarded Honor from VDI in 1985 for his extraordinarily successful development of the modern design teachings and its realization in the practice. His interests include information management for product development and methods and tools for environmentally sound products.

Dr. Veselin Panshef is Sales Manager, at Department Commercial Web Presses, Koenig \& Bauer AG, Würzburg, Germany since 2009. He was a scientific assistant at the Institute for Printing Science and Technology, Darmstadt University of Technology, Germany from 2003 to 2008. His research subject is the service performance for printing machines and printing processes. He attained a Master Degree in economic and mechanical engineering at the Technical University of Ilmenau, Germany. He specialized in Process Quality Management and in 2002 acquired a degree as "Quality Systems Manager" from the European Organization of Quality. His professional experience includes more than ten years as service technician at MAN Roland Druckmaschinen AG in Mexico and Germany.

Edgar Dörsam has been a Professor and Head of the Institute for Printing Science and Technology at the Department of Mechanical Engineering, Darmstadt University of Technology, Germany since 2003. His large industrial experience has been gained from almost ten years work as an engineer and manager in the R\&D-Department of MAN Roland Druckmaschinen AG (Germany). His main research fields include colorimetry, automatization of printing processes, industrial management and advanced technology for printed functionality.

Corresponding author: Tomohiko Sakao, E-mail: tomohiko.sakao@liu.se

\section{Introduction}

Service is getting more attention in today's manufacturing industries, and for several reasons. First, industrial goods manufacturers in today's markets face increasing pressure to exploit new sales or improve their present market position. Service can be a weapon to distinguish those companies from their competitors, especially from low-wage countries (Allmendinger and Lombreglia, 2005). Another reason can originate from the idea of firms treating customers as "non homogeneous" entities (Pine, 1993). For instance, a shoe manufacturer, Adidas-Salomon AG, provides the service of customizing shoes depending on users' characteristics and preferences. Furthermore, firms have reduced 
their efforts on non-core business, and begun purchasing services instead (Prahalad, 2004). All combined, the above results in the "servicification" of the manufacturing sector (Oliva and Kallenberg, 2003).

Thus, service is now an important part of an offering provided by a manufacturing firm. However, only limited knowledge is available for designing pure services (e.g. (Shostack, 1981, Edvardsson and Olsson, 1996)) as compared to that of physical products (e.g. (Pahl and Beitz, 1988)). In addition, the knowledge on how to design services within a solution consisting of both products and services is not sufficient either. Although some literature (e.g. (Morelli, 2003, Tukker and Tischner, 2006, Sakao and Shimomura, 2007)) argues the importance of value proposition using products and services as a means, the knowledge on such practices in industries is scarce. This can result in an inadequate value orientation, which is particularly high in the good manufacturing sector (Kaerner et al., 2004). This is also true in the case of service innovation, because a considerable deficit exists in the field of commercial analysis of industrial services innovation management (Busse, 2005). The results of this deficit reach from insufficient marketability, when the market is established, to in the worst case endangering the existence of the enterprise (Andrew and Sirkin, 2005).

Thus, the knowledge on how to design services effectively and efficiently in practice is indeed in demand in manufacturing industries. This is especially true for manufacturing firms who have developed the infrastructure enabling various services, but have not yet found the service contents.

This article discusses some empirical results obtained from designing services at a manufacturer who had implemented information-communication networks for its customers and adopted a method to design services. The authors propose some working steps for the design method. In addition, the article aims to demonstrate how effectively the method worked for an actual problem in the company. Furthermore, it presents results on the efficiency of such work. To do so, Section 2 describes the motivations originating both from industry and from academia. Then, Section 3 explains the empirical study, while Section 4 discusses the results. Finally, Section 5 concludes the article with some future research implications.

\section{Motivation}

\subsection{Industrial Need and Existing Research}

\subsubsection{Movement toward integration of products and services}

When looking at the movement to integrate products and services (Sakao et al., 2008), it is important to notice a primary driver: a change in the ways of recognizing services from an economic viewpoint. Services have begun to be regarded as a profit center, rather than as cost center. As a practical example from the field of maintenance service, Alsyouf (2007) created a model considering the impact of maintenance on corporate profits. Using the case of a Swedish paper mill company, he demonstrated that maintenance is a function for generating profit. That is just one reason why some manufacturing firms are indeed shifting from the role of product manufacturer to that of service provider.

The shift is represented by the transition model in (Oliva and Kallenberg, 2003). This, however, should be regarded as a shift to integrated offerings of products and services, 


\section{T. Sakao, H. Birkhofer, V. Panshef, and E. Dörsam}

rather than to solely services, as manufacturing firms continue to provide physical products. In fact, this transition model provides a solid base for manufacturers to extend their business using service content.

A trend in line with the above can be found in the marketing domain as well: Vargo and Lusch argue for a new general marketing paradigm promoting a view where there is no distinction made between physical, discrete products and management/information services (Vargo and Lusch, 2004). What matters most is the value provided to customers.

\subsubsection{Service provision by manufacturers and ICT}

Analysis of industries' activities in providing integrated offerings of products and services has revealed that a key to success of such business is securing the access by providers to products in use (Lindahl et al., 2009). The reasons include the capability to measure the performance, and to control and maintain, when necessary, the products. ICT (Information Communication Technology) is a powerful enabler for retaining such access. In other words, ICT is not regarded here as key service content, but rather as a service channel. This is in line with Porter's argument (Porter, 2001) on the usage of the Internet in general, i.e. that the Internet should be viewed as a complement to, not a cannibal of, traditional ways of competing. The strategy is not rendered obsolete by the Internet. In the context of service provision, service contents to be provided are critical as well. This makes it even more important to design service contents, in case ICT is already installed.

\subsubsection{Existing concepts}

In response to these trends, newly generated concepts in academia include Total Care Products (Functional Products) (Alonso-Rasgado et al., 2004, Alonso-Rasgado and Thompson, 2006), which comprises "combinations of hardware and support services", and Product/Service Systems (PSS) (e.g. (Morelli, 2003, McAloone and Andreason, 2004, Tukker and Tischner, 2006). The economically efficient functioning of this concept should be achieved by the proposition of an "intimate business relationship" between the service provider and the customer. As a result, both the provider and the customer obtain benefits through sharing existing business risks (Alonso-Rasgado et al., 2004). Subsequently, the proposal of a "life cycle oriented design" by Aurich et al. (2006) highlights an important step for the "product and technical service design processes" integration. Therefore, with the inclusion of the "Product/Service System" design concept, Aurich's proposal gives a wider base for the meaning of "life cycle". In addition, the concept of mass-customizing service agreements, presented by (Dausch and Hsu, 2006), addresses a dynamic aspect of customers' behavior. As such, this concept provides a framework for customizing manufacturing-based and non-manufacturing-based products by using customers' and providers' business goals. Furthermore, a new discipline called Service/Product Engineering (SPE) (Simboli et al., 2008, Sakao et al., 2009b), formerly called Service Engineering (Sakao and Shimomura, 2007), is being developed. SPE aims at increasing the value of artifacts by focusing on service.

In common to these concepts above, service activity is beginning to be increasingly incorporated into the design space, an area which has been traditionally dominated by physical products in manufacturing industries.

\subsubsection{Need of methodical support}

For practitians to carry out engineering tasks, methodical support is in general effective 
and efficient. Thus, in the case of designing a combination of services and products, methodical support may be demanded (Sakao et al., 2009a). Methodical support in this case can be realized by providing design procedures and design-object models with designers. Traditionally in mechanical product design, an object model has been regarded useful. For instance, Beitz and Feldhusen state machine design is based on a description of the part to be produced, which is created with the aid of models of the part (Beitz and Feldhusen, 1991). In addition, those models are useful to refine the design object (Hoover et al., 1991). In developing service activities as well, it is argued that such a model is beneficial in spite of the relative difficulty to model service activities (Bitran and Pedrosa, 1998).

To develop service contents, it is important to select promising spaces where customers appreciate changes. For this purpose, an interesting method has been developed (Ulwick, 2002). One idea adopted in this method is that customers recognize, in such promising spaces, high importance but low satisfaction. Thus, this method asks customers to give ratings to importance and satisfaction of several potentially desired outcomes. As a result, the levels of opportunity for each outcome can be obtained from the formula below.

opportunity $=$ importance + (importance - satisfaction $)$

This method is reported to have been successful in actual markets.

\subsection{Developed Methods and Tools for Service Design}

\subsubsection{Models and design methods}

In the field of marketing and management, Shostack has proposed an object model of services (Shostack, 1981). The model contains "service element" and "product element", which are provided and utilized, respectively. In addition, in the area of methodological service development, the concept for a new service development, proposed by (Edvardsson and Olsson, 1996), gives a detailed description of what a service customer needs and how this can be achieved. This concept focuses on various customers with different individual business processes having three types of design: service concept design, service system design and service process design. However, the main focus of both of those studies is on how to provide the service activities, leaving out the design of physical products.

Total Care Products (Functional Products) (Alonso-Rasgado et al., 2004, AlonsoRasgado and Thompson, 2006), which comprises "combinations of hardware and support services", is also a concept of connectivity. They propose to adopt the structured analysis and design technique (SADT) (Marca and McGowan, 1988) for modelling service support systems, and also propose a service design process. As SADT has been created to describe activities, it can only be applied to the part of service activities that fail to address the critical part: integration of products and services.

Modeling integrated combinations of products and services has been tackled under the research of Service/Product Engineering (SPE) (Simboli et al., 2008, Sakao et al., 2009b), formerly called Service Engineering (Sakao and Shimomura, 2007). Here, a service is defined as "an activity that a provider causes a receiver, usually with consideration, to change from an existing state to a new state that the receiver desires, where both contents and a channel are means to realize the state change". Service contents are provided by a service provider and delivered through a service channel. Physical products are either the 
service contents or the service channel. Service activities support service contents to be transferred or activate service channels. The model has been developed to describe such critical information as provider/receiver, receiver's state change, functions of service activities and physical products (see details in (Maussang et al., 2006, Sakao et al., 2009b)). Based on this model, Shimomura et al. have developed an evaluation method for services (see details in (Shimomura and Sakao, 2007)). It is extended from the QFD (Quality Function Deployment) (Akao, 1990) technique, where the voice of customers in the QFD model are replaced with RSPs (receiver state parameters; referring to value or cost). The new model and design method formed a base for computer software, named Service Explorer (see details in (Sakao et al., 2009b)), to support designers.

\subsubsection{Necessity to validate with actual cases in industry}

Although several theoretical methods/tools have been developed successfully as reviewed above, little knowledge is available from the practical viewpoint of industry. Thus, sufficient evidence is not available to answer several important research questions, (RQ) as follows:

RQ1. Are the methods/tools effective in a case with real industrial scale?

RQ2. How efficient are the methods/tools for a real world problem?

RQ3. To which types of industries/offerings are the methods/tools applicable?

RQ4. How do the methods/tools fit into the work process in companies?

In order to answer these questions, it is necessary to validate the proposed methods/tools with industrial cases.

\section{Empirical Study}

\subsection{Target company and its strategies}

To answer the questions in Section 2.2.2, the method of case study (Eisenhardt and Graebner, 2007) has been adopted. Section 3 introduces the case, in which some of the methods/tools explained in Section 2.2.1 were applied to an early phase of an offering development in a German manufacturing company. This company provides a kind of production machine to customers who produce products using additional contents. The machines can be characterized as investment machines, are quite complex with control by computer, and have a significant cost (the order ranging from 100 thousand up to 10 million Euros). The market size is several billion Euros and has been shrinking over the last several years, which partially makes the competition in this market quite tough.

While often being considered a traditional investment machine manufacturer, this company has always pursued the aim of offering the best service activities in the market. As such, it has begun to increase its focus on services for its customers, and has established an efficient service organization with modern tools to supply customized services in combination with the machines to offer an optimal solution for the customer. The service activities range from technical maintenance and supplying spare parts to offering full service contracts and online services using ICT technologies. An example of this is implementing a network for communication with machine users using ICT, meaning that the company had a basic facility for services, especially e-services.

This company, in fact, regards the following three types as the crucial set of instruments to provide customers with value: the physical product, the communication 
An effective and efficient method to design services: empirical study

infrastructure, and the service contents. Yet, they lacked sufficient service contents. Thus, the target here was developing contents for services provided by the company with its customers. In a traditional sense, no service (i.e. inspection and maintenance) meant high value from high quality machines. However, it should be emphasized that this company has strategically shifted to a role as provider of offerings (i.e. products and services), and as a result the service contents by which the company can charge customers by providing service activities was missing.

\subsection{Developed working steps and adopted methods/tools}

The authors developed some working steps based on the method to identify opportunities (Ulwick, 2002) and the service evaluation method (Shimomura and Sakao, 2007), so that they fit well with the information assets of a given company. The reason why those methods were adopted is their well-described procedures and the available software partially supporting those procedures. As depicted in Figure 1, they consisted of seven steps (from 0 to 6). If customers' requirements on their value and costs already exist, Step 0 will be omitted. Step 3 adopts the method by Ulwick, while Step 4 that of Shimomura et al. Step 4, named "translation to design parameters", is among the core steps. It uses the information from customers and specialists from the provider's side. The former information is represented by quantitative importance/satisfaction on the given customer value/cost, and can be collected by a simple questionnaire. The latter is either about services or products provided by the company, and can be gathered using matrices similar to those used in QFD. 
T. Sakao, H. Birkhofer, V. Panshef, and E. Dörsam

Figure 1 The working steps developed and adopted at the company

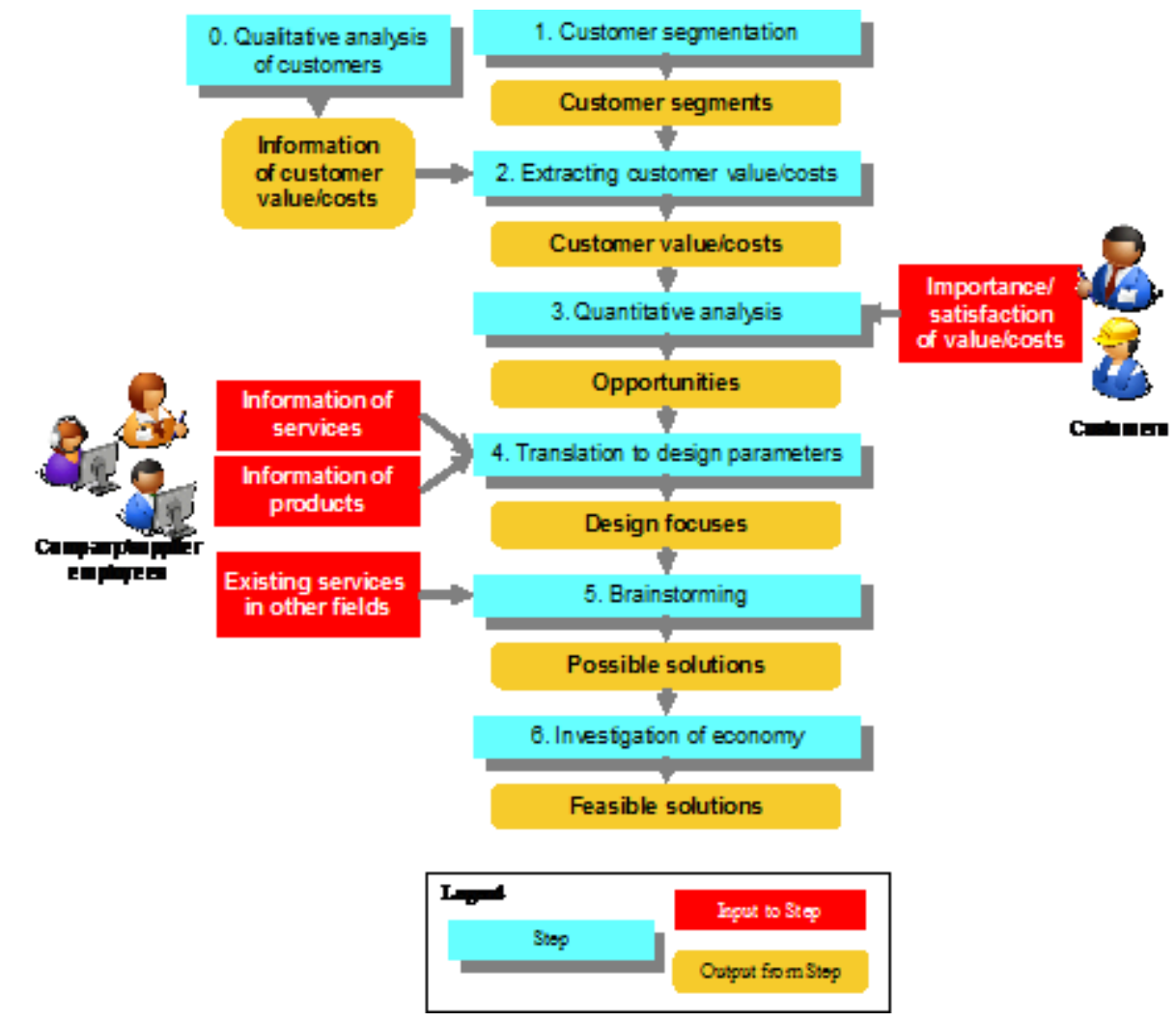

Note: "Output from Step" in the legend is also an input to the next step (except for the final output).

Once the design focuses are obtained from Step 4, brainstorming with employees with specific knowledge and responsibility will be held as Step 5. This is followed by Step 6, which is investigation of economic feasibility of possible solutions generated from Step 5. Finally, feasible solutions are produced. Since some steps, especially Steps 1, 5 and 6, are quite familiar to companies in general, the new essence of these working steps exists in Steps 2, 3, and, particularly, 4. Thus, these working steps have proper contrivance; while they are familiar to widespread ways of working in companies in general, they are adapted to addressing offerings.

\subsection{Results}

This company already had substantial information about customer requirements. This information originates from in-depth interviews with customers and periodic meetings with important customers. Therefore, Step 0 was omitted.

In Step 1, geographical segmentation of customers was adopted, as services were provided by this company through localized and independent branches in different countries, and because the geographical segmentation may produce information useful for customization by services.

Step 2 integrated various customer value and costs into 12 RSPs (receiver state parameter) such as cost of repair/maintenance, quality of final product, available 


\section{An effective and efficient method to design services: empirical study}

operation time of machine, and immediate availability of machine (see below for an explanation).

In Step 3, a customer survey was completed asking the importance and the satisfaction of each RSP in the scale from 1 (least important) to 7 (most important). In this survey, 51 effective answers from the company's clients in five countries were collected. Figure 2 shows the importance of the 12 RSPs in the average of all the answers, with the remaining 9 ones anonymous.

Figure 2 Importance of the 12 RSPs obtained from the survey (average from 51 customers)

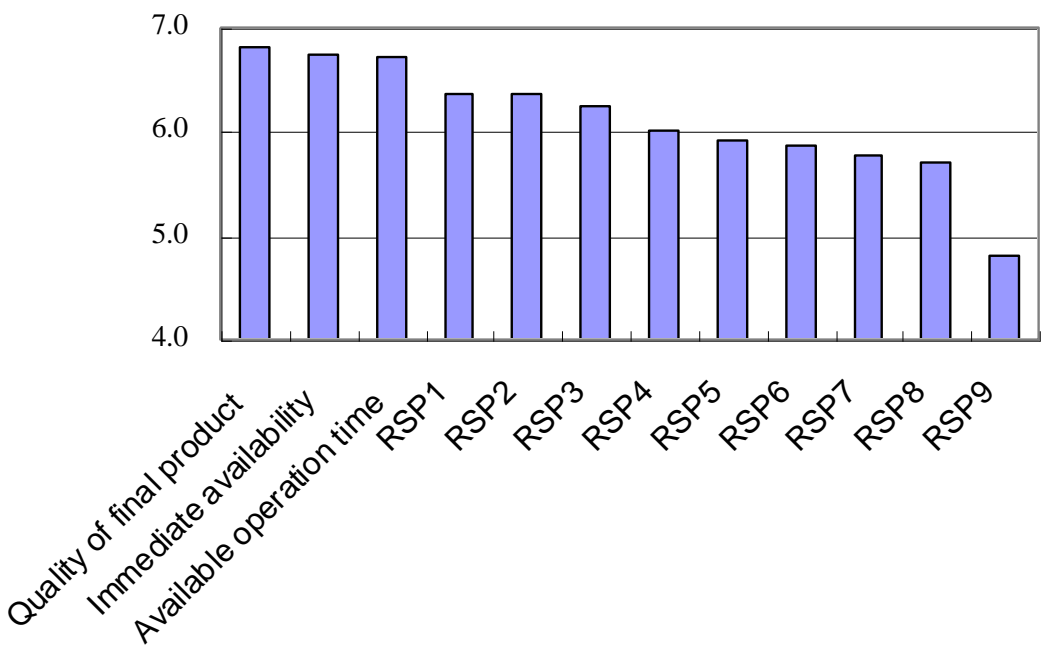

The top three important RSPs were as follows (all three were more or less equally important; the average importance was over 6.5).

- Quality of final product - This refers to the quality of the final product given to the machine user's customer.

- Available operation time of machine - This means the percentage of time that the machine is available for work.

- Immediate availability of machine - This reflects the need for having the machine able to run just at the moment that a job needs to be done. In contrast to "available operation time of machine", requiring this property means that the machine is available when needed; this property does not care about the whole ratio of time when the machine is available.

Based on the formula shown in Section 2.1.4, the opportunities were also calculated. The cost of repair/maintenance received the highest opportunity score, which was followed by the above, i.e. immediate availability of machine, available operation time of machine, and quality of final product. Therefore, it was derived that the three value should be targeted at the same time with the need to decrease the cost of repair/maintenance.

In Step 4, to describe the information of products/services on Service Explorer, employees in various divisions within the company provided the relevant information. 


\section{T. Sakao, H. Birkhofer, V. Panshef, and E. Dörsam}

Interviews were carried out with 10 divisions such as $R \& D$, service development, maintenance service, product management, quality control, hard and software upgrades, service parts, service sales, and consulting services. In addition, each RSP was developed into design parameters, which were verified by those employees. A portion of a partial matrix and a graphical deployment, as an example, are shown in Figures 3 and 9, respectively. The constructed model was so large that 173 design parameters (and 31 entities, meaning physical products or service persons) were included.

Using the importance of RSPs and the correlation between RSPs and design parameters, the importance of design parameters was obtained as well; "malfunction frequency", "extend of malfunction", and "time for setup" were the most important. This is reasonable because customers appreciate high availability to a high degree. These important design parameters are included in the design focuses, the output of Step 3. Figure 3 is a screen dump of Service Explorer showing the results of the evaluation. Note that some parts on the dump are blacked out due to the company's confidentiality.

Figure 3 A screen dump of the evaluator of Service Explorer

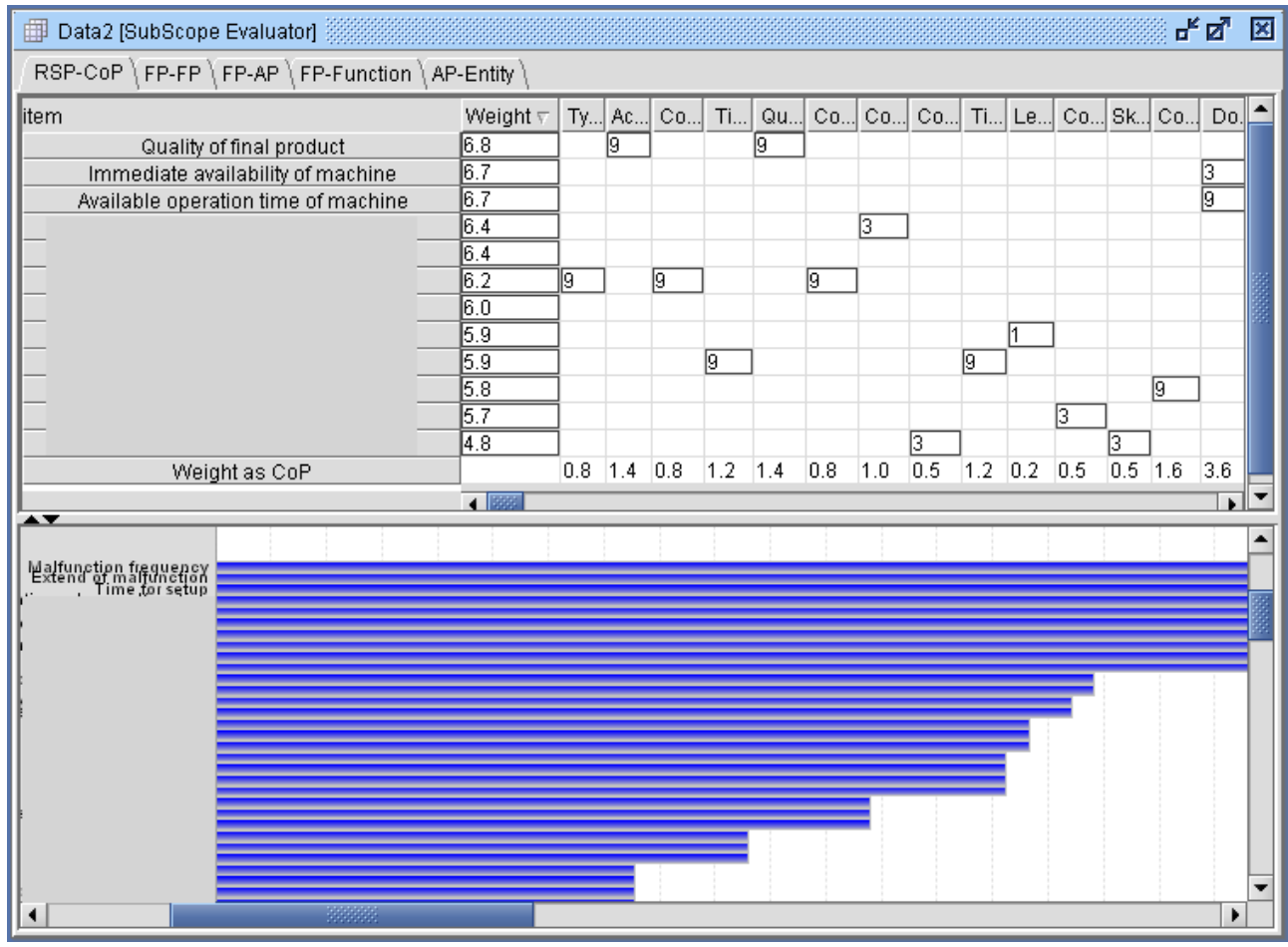

Note: Some parts are masked due to the confidentiality.

In Step 5, after selecting the RSP "immediate availability of machine", employees in the product development division searched for potential offerings with the help of the model in Service Explorer whose upper part is shown in Figure 4. The model shows how achieving the RSP is influenced by three functions: "provide setup time", "prevent machine breakdown", and "repair machine breakdown". Three solutions, among those obtained from the brainstorming sessions, are explained as follows.

(1) Machine with self-maintenance functionality 


\section{An effective and efficient method to design services: empirical study}

A function, "repair machine breakdown", which refers to the service activity after a malfunction happens, is deployed into functions such as "find problem", "find solution", "implement solution", and "confirm status" as shown in the right-hand side of Figure 4. These functions could be fulfilled by physical products existing in other fields. Additional equipment utilizing robotics technologies are one type of such measure. In addition, machines with "self-maintenance functionality" (Lee and Wang, 1999), taking advantage of artificial intelligence techniques, are another option. This is more feasible because no additional hardware is required. Self-maintenance maintains its functionality by embedded software belonging to the physical product.

As for decreasing the cost, this solution may be positive given its potential to decrease the personnel cost for maintenance engineers, which is quite high in the developed countries.

(2) Staff with quick response

The above-mentioned function "repair machine breakdown" is also deployed in the functions "get contacted", "offer response time", "find problem", and "find solution" as shown in Figure 4. From those design parameters such as "hotline availability", and "technician availability", it is understood that not merely the availability of the support line but also that of staff with sufficient technical knowledge is crucial. This analysis allowed the generation of a solution for making responses from such staff quicker.

This solution might work against decreasing the cost for customers, because they may be charged more than before. Therefore, it is critical to keep the ratio of benefit and cost for customers upon developing this solution into details in Step 6.

(3) Machine and operation with less-frequent malfunction

A function, "prevent machine breakdown", is deployed into functions such as "perform preventive maintenance", "provide machine reliability", and "train operator to prevent breakdown" as shown in the left part of Figure 4. This means that preventing machine faults requires investigating not only the machine itself, but also the factors of the operators, namely customers. These functions are critical, because the most important design parameter was found to be "malfunction frequency". To improve from this aspect, the company has already identified several "hot spots" in the process of the customers and several measures for them in a different project. 
Figure 4 A screen dump of the models in Service Explorer (portion of a model)

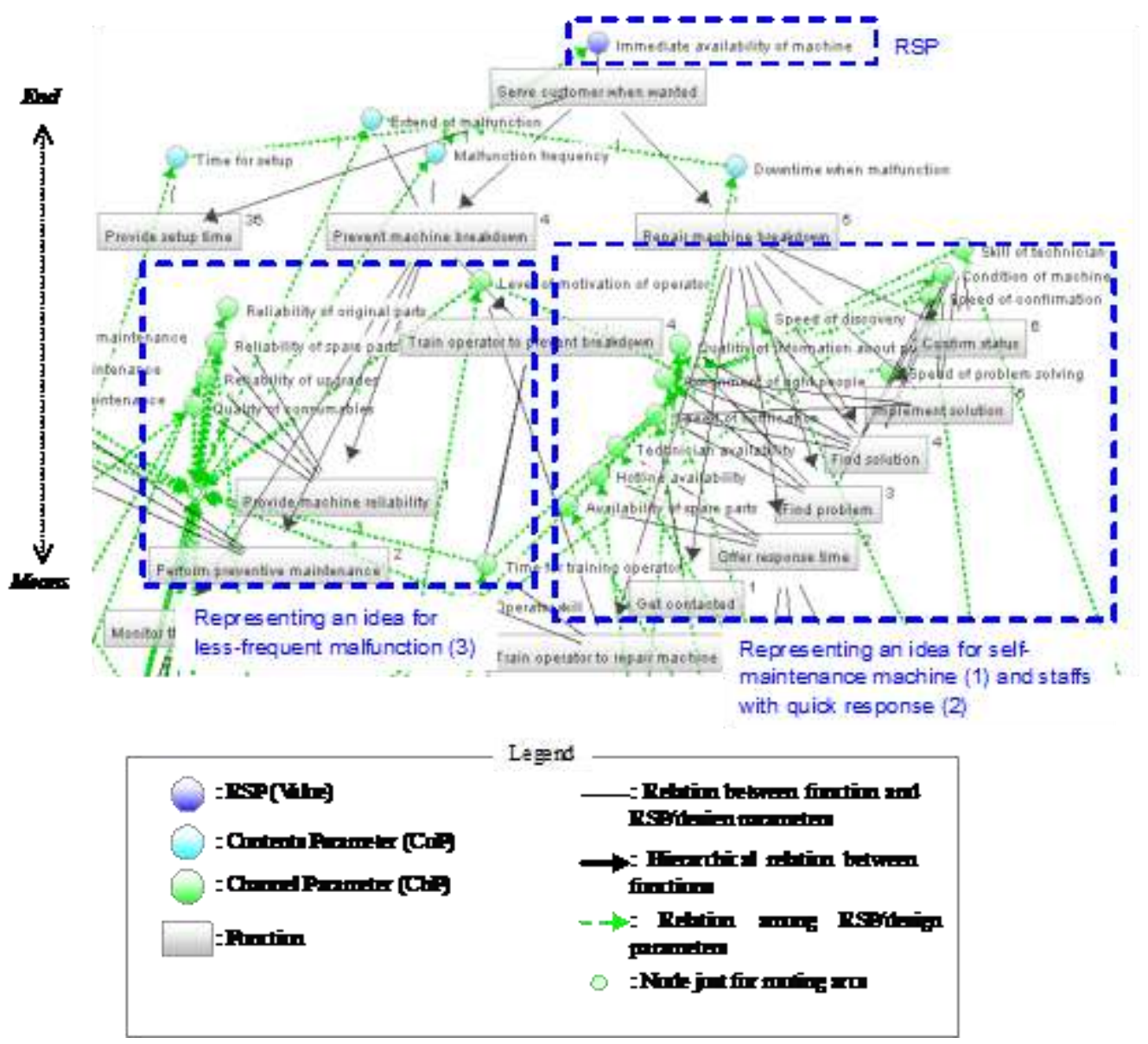

Note: The lower part of the model is not shown due to the confidentiality.

This empirical study ended with Step 5, since Step 6 is relatively common in industry. The entire study took approximately 5 person-months to complete, excluding the hours of the respondents to the questionnaire outside the company.

\subsection{Findings}

\subsubsection{Effectiveness and efficiency}

The empirical study revealed that the methods support the offering development team at the company to generate offerings effectively. Especially, the RSPs that the team focused on are demanded exactly from its customers. As such, all the identified solutions are effective in influencing the customers' demands. In addition, RSP refers to the receiver's own measurable state change, not merely to its need or want in general. Namely, RSP points specifically to what receivers attempt to optimize. Thus, it is objectively certain that measures affecting important RSPs are appreciated by customers. Namely, the 


\section{An effective and efficient method to design services: empirical study}

models work as a simulator of customer satisfaction.

The model allowed the team to seek measures from both physical products including software and service activities for realizing value for the target receiver. As explained in Section 3.3, the first option (by a physical product) and the second (by service activity) were generated from the same part of described functions (see the right part of Figure 4). This is impossible without the object model with this property. It should be again emphasized that what was intended to be delivered is value, not only quality, for instance, as shown by the RSP "immediate availability of machine".

Sharing and focusing the on identified focuses within the team could eliminate the efforts to explore other areas that are not customers' hot spots. Namely, they could reach effective measures with fewer efforts. Thus, the efficiency was also proven. Consider, for instance, the difference between the importance of the top three RSPs and that of the last three is about 1.3, which cannot be regarded as negligible on the scale 1 to 7 .

\subsubsection{Success factors}

Two success factors are raised here. First, the characteristics of the addressed services, i.e. services with investment machines connected to manufacturers, worked positively. The main difference between this type of offering and traditional sales of physical products, the opportunity to control the products on a remote basis, was manageable by the working steps adjusted to offerings of services and products based on those for products.

The second success factor concerns an organizational issue. This company already had implemented a process for working as a cross-functional team at an early stage for developing new products. Having opportunities that people from different divisions (e.g. product development, $\mathrm{R} \& \mathrm{D}$, marketing, maintenance, customer support) in a company was a key condition for this method to work, something which made Steps 4 and 5 especially smooth. However, other companies without such opportunities at present are expected to face more difficulty to do so.

\subsubsection{Identified difficulties}

A big difficulty revealed in this empirical study was the preparation of the needed ontology in a consistent manner. The design parameters were especially found difficult to consistently prepare. Needless to say, different terms for the same meaning are not allowed to be used in the model. In addition, a hierarchy of design parameters must be kept, because a part of a hierarchy sometimes shows up in a different hierarchy. For instance, design parameters related to inspection are used to describe repair, as inspection is usually a part of repair. It should be noted that 173 design parameters were used in this industrial case.

\section{Discussion}

The study has shown that the methods assist designers to work in a structured and efficient way by providing the designer with the required concepts that are to be considered when developing new services. It proved that the proposed working steps can work effectively to highlight the critical design parameters to develop new service concepts. The method has also presented new solutions that target the detected critical design parameters. The rest of this section discusses the results more concretely, and also attempts to answer the research questions raised in Section 2.2.2. 


\section{T. Sakao, H. Birkhofer, V. Panshef, and E. Dörsam}

The proposed working steps proved to be effective and efficient for developing a set of physical products and service activities, as explained in Section 3.4. It was also verified that the model represents the ways of both physical products and service activities to realize value in the same manner. It should be noted that the model provides a higher probability for the team to discover more options by having descriptions of functions, which are intermediate between RSPs and products/service activities, than without having such information (e.g. describing entities directly). In addition, it should be emphasized that this study is a new piece of evidence that a marketing-oriented method and a design method can work in a synergetic way for service design ((Ulwick, 2002) and (Shimomura and Sakao, 2007) adopted in this case).

Service Explorer as a computerized tool proved to be effective on the following two points. First, its ability to manage information on the offerings was useful. Actually, it not only stored the model appropriately, but also managed the relations among the elements in the model. Thus, users could find the concerned information with ease based on the information management by Service Explorer. Second, the power of computing helped considerably, especially upon carrying out the evaluation by automating the calculation procedures.

It was pointed out in Section 3.4 that the model was fairly large, and that special efforts were needed to prepare the ontology. However, most of the parts can be reused for a similar purpose, and substantial time could be saved in the future. For instance, few editing models will be necessary when new services are developed for a different market or in a different time. Thus, the actual time for various occasions could be reduced substantially, once the results of the work steps are available. As an answer to RQ1, it is argued that the adopted methods are effectively applicable to an actual problem with ordinary scale in industry.

To answer RQ2, five person-months were input for Steps 1 to 5 to obtain the explained outcome. It should be emphasized that the method for prioritizing opportunities helped to decrease the time substantially. On the other hand, not much insight has been obtained to answer RQ3. What has been revealed is that the methods are well applicable to services with investment machines. The type of machines implies the criticality to customers. However, more through study will be needed to fully answer this question.

The model and the methods take advantage of a widespread engineering discipline: the model is built up based on such engineering concepts as functions and entities. It introduces new concepts, service activities and value/costs, out of necessity. The method is also based on "extended QFD". Since QFD is a familiar method in the engineering field, the developed method is expected to receive high acceptance from potential users in the manufacturing industries. One answer to RQ4 is that the methods fit well with work processes similar to those of QFD.

\section{Conclusion and Future Research Implications}

In conclusion, this article has demonstrated the capability of the service design method based on Service/Product Engineering to support development of offerings with a set of products and services in an actual problem. The method was validated through application to services in the manufacturing industry. Designers can use the method to their advantage, so that both service activities and physical products effective for customer value are generated from a large design space, but with focus only on relatively 
An effective and efficient method to design services: empirical study

important elements.

Future work includes the development of a precise method for quantitative comparison among the measures to provide the value. This means comparison in terms of the increase in value additionally obtained by a receiver over the needed cost by a provider. To do so, for the numerator Conjoint Analysis (Green and Srinivasan, 1978) can be borrowed, as previously introduced in Section 3.2.3. For the denominator, it is needed to calculate costs for implementing a function by the use of Functional Cost Analysis (Pugh, 1990), which addresses the costs caused by physical parts, as well as Activity-based Costing (Cokins, 2001) for incorporating the costs of employees' processes. This contributes to select the best measure among some candidates. Other future work includes validation through service customization (e.g. (Dausch and Hsu, 2006)). Furthermore, Service Explorer can be improved by taking advantage of the power of computation. One example is support through several types of reasoning. With this background in mind, there has already been an attempt to implement a reasoning engine for abduction (Takeda et al., 2003).

\section{Acknowledgement}

The authors would like to express special gratitude to the employees of the anonymous company in Germany for their active cooperation in the application presented in Section 3. Mr. Jens Mündler from Darmstadt Univ. of Technology also cooperated to achieve this application, and is hereby thanked. In addition, our gratitude is extended to Prof. Tamio Arai and Dr. Tatsunori Hara from the Univ. of Tokyo, and Prof. Yoshiki Shimomura from Tokyo Metropolitan Univ., for providing the authors with Service Explorer and making beneficial suggestions in the applications.

This research was partially supported by a Research Fellowship Program by Alexander von Humboldt Foundation in Germany, as well as by the Swedish Association of Graduate Engineers (Sveriges Ingenjörer).

\section{References and Notes}

Akao, Y. (1990) Quality Function Deployment, Productivity Press, Portland, OR.

Allmendinger, G. and Lombreglia, R. (2005) Four Strategies for the Age of Smart Services, Harvard Business Review, Vol. 83, October, DOI: 10.1225/R0510J.

Alonso-Rasgado, T. and Thompson, G. (2006) 'A rapid design process for Total Care Product creation', Journal of Engineering Design, Vol. 17, No. 6, pp. 509 - 531.

Alonso-Rasgado, T., Thompson, G. and Elfstrom, B. (2004) 'The design of functional (total care) products', Journal of Engineering Design, Vol. 15, No. 6, pp. 515-540.

Alsyouf, I. (2007) 'The role of maintenance in improving companies' productivity and profitability', International Journal of Production Economics, Vol. Vol. 105, pp. pp.70-78. Andrew, J. and Sirkin, H. L. (2005) Innovation 2005 - Senior Management Survey Report, The Boston Consulting Group, Boston, Massachusetts (USA).

Aurich, J. C., Fuchs, C. and Wagenknecht, C. (2006) 'Life Cycle Oriented Design of Technical Product-Service Systems', Journal of Cleaner Production, Vol. Vol. 14, pp. 
T. Sakao, H. Birkhofer, V. Panshef, and E. Dörsam

pp.1480-1494.

Beitz, W. and Feldhusen, J. (1991) 'Management systems and program concepts for an integrated CAD process ', Research in Engineering Design, Vol. 3, No. 2, pp. 61-74.

Bitran, G. and Pedrosa, L. (1998) 'A structured development perspective for service operations', European Management Journal, Vol. 16, No. 2, pp. 169-189.

Busse, D. (2005) Innovation management of industrial services: theoretical bases and practical scope for design (Innovationsmanagement industrieller Dienstleistungen: theoretische Grundlagen und praktische Gestaltungsmöglichkeiten), Dt. Univ.-Verl., Wiesbaden.

Cokins, G. (2001) Activity-based Cost Management, John Wiley \& Sons, New York.

Dausch, M. and Hsu, C. (2006) 'Engineering service products: the case of masscustomising service agreements for heavy equipment industry', International Journal of Services Technology and Management, Vol. 7, No. 1, pp. 32 - 51

Edvardsson, B. and Olsson, J. (1996) 'Key concepts for new service development', The Service Industries Journal, Vol. 16, No. 2, pp. 140-164.

Eisenhardt, K. M. and Graebner, M. E. (2007) 'Theory Building from Cases: Opportunities and Challenges', Academy of Management Journal, Vol. 50, No. 1, pp. 2532.

Green, E. and Srinivasan, V. (1978) 'Conjoint Analysis in Consumer Research: Issues and Outlook', Journal of Consumer Research, Vol. 5, pp. 103-123.

Hoover, S. P., Rinderle, J. R. and Finger, S. (1991) 'Models and abstractions in design', Design Studies, Vol. 12, No. 4, pp. 237-245.

Kaerner, H., Kasper, M. and Mattmüller, R. (2004) After-Sales: the service provide the profit - how you connect products successfully with services (After-Sales: der Service macht den Gewinn - wie Sie Produkte erfolgreich mit Dienstleistungen verbinden), Frankfurter Allg. Buch im FAZ-Inst., Frankfurt am Main.

Lee, J. and Wang, B. (Eds.) (1999) Computer-Aided Maintenance, Dordrecht, The Netherlands, Kluwer Academic Publishers.

Lindahl, M., Sakao, T. and Rönnbäck, A. Ö. (2009) 'Business Implications of Integrated Product and Service Offerings', CIRP IPS2 Conference 2009, pp. 165-172.

Marca, D. A. and Mcgowan, C. L. (1988) SADT TM; Structured Analysis and Design Technique, Prentice-Hall, New York.

Maussang, N., Zwolinski, P. and Brissaud, D. (2006) 'A Representation of a ProductService System During its Design Phase - A Case Study of a Helium Liquefier', 13th CIRP International Conference on Life Cycle Engineering, pp. 555-561.

McAloone, T. C. and Andreason, M. M. (2004) 'Design for Utility, Sustainability and Social Virtues, Developing Product Service Systems', International Design Conference, pp. $1545-1552$.

Morelli, N. (2003) 'Product-service systems, a perspective shift for designers: A case study: the design of a telecentre', Design Studies, Vol. 24, No. 1, pp. 73-99.

Oliva, R. and Kallenberg, R. (2003) 'Managing the transition from products to services', International Journal of Service Industry Management, Vol. 14, No. 2, pp. 160-172.

Pahl, G. and Beitz, W. (1988) Engineering Design: A Systematic Approach, SpringerVerlag, London.

Pine, J. (1993) Mass Customization: the New Frontier in Business Competition, Harvard Business School Press, Boston, MA.

Porter, M. E. (2001) 'Strategy and the Internet', Harvard Business Review, Vol. 79, March, pp. 62-78. 
An effective and efficient method to design services: empirical study

Prahalad, C. K. (2004) 'The Co-creation of Value. Invited Commentaries on "Evolving to a New Dominan Logic for Marketing"', Journal of Marketing, Vol. 68, No. 1, pp. 23.

Pugh, S. (1990) 'Total Design', Prentice Hall, pp. 207-208.

Sakao, T., Napolitano, N., Tronci, M., Sundin, E., and Lindahl M. (2008) 'How Are Product-Service Combined Offers Provided in Germany and Italy? - Analysis with Company Sizes and Countries -', Journal of Systems Science and Systems Engineering, Vol. 17, No. 3, pp. $367-381$.

Sakao, T., Sandström, G. Ö. and Matzen, D. (2009a) 'Framing design research for service orientation through PSS approaches', Journal of Manufacturing Technology Management, provisionally accepted to appear.

Sakao, T. and Shimomura, Y. (2007) 'Service Engineering: A Novel Engineering Discipline for Producers to Increase Value Combining Service and Product', Journal of Cleaner Production, Vol. 15, No. 6, pp. 590-604.

Sakao, T., Shimomura, Y., Sundin, E. and Comstock, M. (2009b) 'Modeling Design Objects in CAD System for Service/Product Engineering', Computer-Aided Design, DOI: 10.1016/j.cad.2008.06.006, Vol. 41, No. 3, pp. 197-213.

Shimomura, Y. and Sakao, T. (2007) 'A Service Evaluation Method for Service/Product Engineering', International Conference on Engineering Design, CD ROM.

Shostack, G. L. (1981) 'How to Design a Service', in Donnelly, J. H. and George, W. R. (Eds.): Marketing of Services, American Marketing Association, pp. 221-229.

Simboli, A., Raggi, A., Petti, L., Shimomura, Y. and Sakao, T. (2008) 'Service/Product Engineering as a potential approach to value enhancement in supply chains', Progress in Industrial Ecology, Vol. 5, No. 4, pp. 325-348.

Takeda, H., Sakai, H., Nomaguchi, Y., Yoshioka, M., Shimomura, Y. and Tomiyama, T. (2003) 'Universal Abduction Studio -Proposal of A Design Support Environment for Creative Thinking in Design-', 14th International Conference on Engineering Design 2003, CD ROM.

Tukker, A. and Tischner, U. (2006) New Business for Old Europe, Greenleaf Publishing, Sheffield.

Ulwick, A. W. (2002) Turn Customer Input into Innovation. Harvard Business Review, Vol. 80, January, pp. 91-97.

Vargo, S. L. and Lusch, R. F. (2004) 'Evolving to a New Dominant Logic for Marketing', Journal of Marketing, Vol. 68, No. 1, pp. 1-17. 